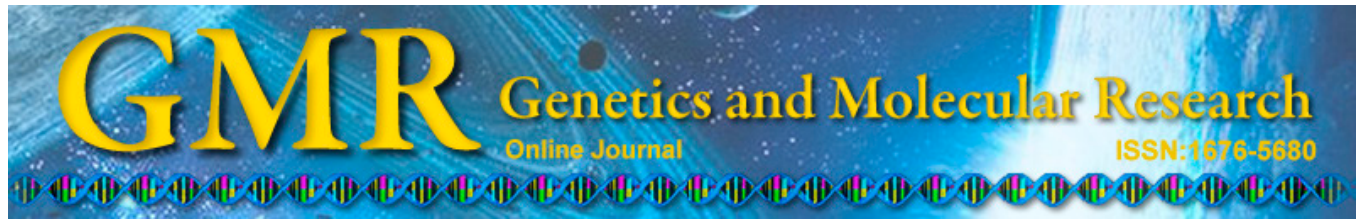

\title{
Interleukin-10 gene promoter polymorphism and risk of liver cirrhosis
}

\author{
Y. Liu ${ }^{1}$, M.C. Yu ${ }^{2}$, A.Q. Zhang ${ }^{1}$, Y.B. Wang ${ }^{1}$, K. Jiang ${ }^{1}$ and J.H. Dong ${ }^{1}$ \\ ${ }^{1}$ Department of Hepatobiliary Surgery, Chinese PLA General Hospital, \\ Beijing, China \\ ${ }^{2}$ Department of Hepatobiliary Surgery, Zhangqiu People's Hospital, \\ Affiliated Hospital of Jining Medical University, Jinan, China \\ Corresponding authors: J.H. Dong / K. Jiang \\ E-mail: zhaop92622@163.com / jiangkai1212@yeah.net
}

Genet. Mol. Res. 14 (1): 1229-1234 (2015)

Received September 6, 2013

Accepted May 4, 2014

Published February 13, 2015

DOI http://dx.doi.org/10.4238/2015.February.13.1

ABSTRACT. We conducted a hospital-based case-control study to assess the association between $I L-10-592 \mathrm{~A} / \mathrm{C}, I L-10-819 \mathrm{C} / \mathrm{T}$, and $I L-10-1082 \mathrm{~A} / \mathrm{G}$ polymorphisms and the risk of liver cirrhosis in a Chinese population. This 1:1-matched case-control study included 192 patients from the Chinese PLA General Hospital. Genotypes of $I L-10-592 \mathrm{~A} / \mathrm{C}, I L-10-819 \mathrm{C} / \mathrm{T}$, and $I L-10-1082 \mathrm{~A} / \mathrm{G}$ were detected by polymerase chain reaction amplification-restriction fragment length polymorphism analysis. Conditional regression analysis showed that individuals carrying the $I L-10-1082 \mathrm{G}$ allele had an only slightly increased risk of liver cirrhosis, with an adjusted odds ratio $(95 \%$ confidence interval) of 2.14 (0.97-1.68). However, we did not identify a significant association between polymorphisms in $I L-10-592 \mathrm{~A} / \mathrm{C}$ and $I L-10-819 \mathrm{C} / \mathrm{T}$ and the risk of liver cirrhosis. These findings may provide important clues for future studies of early detection screening of liver cirrhosis.

Key words: Interleukin-10 gene; Liver cirrhosis; Polymorphism 


\section{INTRODUCTION}

Liver cirrhosis is an important factor in the development of hepatocellular carcinoma, which is induced by hepatitis B virus (HBV) or hepatitis C virus (HCV) infection, drugs abuse, or alcohol consumption (EASL, 2010). These risk factors involve a sequence of chronic inflammation and fibrosis, during which different inflammatory and immune cytokines play a key role in the development of liver cirrhosis.

Interleukins are a diverse group of small cell-signaling protein molecules or cytokines, which function to alter the immune system in humans (Lippitz, 2013; Tsai et al., 2013). The interleukin-10 gene $(I L-10)$ is located on chromosome $1(1 \mathrm{q} 31-1 \mathrm{q} 32)$ and is a pivotal immunoregulatory cytokine with an important role in many aspects of the immune response. IL-10 is a T helper-2 (Th2) cytokine that downregulates Th1 effector mechanisms. Natural killer cell- and Th1 cell-mediated immune responses play a role in protection against HCV and hepatitis virus infection (Koziel, 2005). Previous studies reported that the levels of interleukin- 8 and interferon-r inducible protein-10 were higher in liver cirrhosis patients compared with healthy subjects (Andersen et al., 2011).

DNA sequences and their variations reflect the human evolutionary process. Singlenucleotide polymorphisms (SNPs) in $I L-10$ may alter the production of cytokines, and a number of polymorphisms appear to control the level secretion of IL-10 (Reuss et al., 2002). IL-10 has 3 common SNPs at positions $-1082,-819$, and -592 with respect to the transcription initiation site (Turner et al., 1997). However, there have been no studies in China to investigate the association between $I L-10$ polymorphisms and the risk of liver cirrhosis.

To further assess the association between $I L-10$ variants and the risk of liver cirrhosis, we conducted a hospital-based case-control study by genotyping 3 common SNPs in $I L-10$ $(I L-10-592 \mathrm{~A} / \mathrm{C}, I L-10-819 \mathrm{C} / \mathrm{T}$, and $I L-10-1082 \mathrm{~A} / \mathrm{G})$ in a Chinese population.

\section{MATERIAL AND METHODS}

\section{Patients}

A total of 215 patients with liver cirrhosis were randomly or sequentially recruited at the Department of Hepatobiliary Surgery, Chinese PLA General Hospital. All liver cirrhosis patients were diagnosed histopathologically or based on the specific morphological criteria of liver cirrhosis with ultrasound, computed tomography, or magnetic resonance imaging. Patients who received organ transplantation or had advanced-stage hepatocellular carcinoma were excluded from the case group. A total of 192 patients agreed to participate in this study (participation rate: $89.3 \%$ ).

Control subjects were collected from the health examination center of the Chinese PLA General Hospital; sex- and aged-matched control subjects were recruited for each case subject. Control subjects with any digestive disease were excluded from the study.

\section{Serological testing}

All patients were asked to provide $5 \mathrm{~mL}$ peripheral blood, which was collected and stored at $-80^{\circ} \mathrm{C}$ before DNA extraction. Hepatitis B surface antigen (HBsAg) and anti-HCV antibody were tested using an enzyme-linked immunosorbent assay with a commercial kit 
(Hepanostika, bioMerieux, Boxtel, The Netherlands) and a recombinant immunoblot assay (RIBA Innogenetics, Ghent, Belgium). All patients read and signed an informed consent form.

\section{DNA extraction and SNP genotyping}

Genomic DNA extraction from the 5-mL peripheral blood samples was conducted using the TIANamp Blood DNA Kit (Tiangen Biotech, Beijing, China).

The 3 polymorphisms in $I L-10$ were detected by polymerase chain reaction amplification-restriction fragment length polymorphism analysis. Primer sequences of the 3 polymorphisms for polymerase chain reaction were designed using the Sequenom Assay Design 3.1 software (Sequenom, San Diego, CA, USA) (Table 1). Each amplification reaction included 50 ng genomic DNA, $200 \mu \mathrm{M}$ dNTP, 2.5 U Taq DNA polymerase (Promega, Madison, WI, USA), and $200 \mu \mathrm{M}$ primers in a total volume of $20 \mu \mathrm{L}$. The following cycling program was used: preliminary denaturation at $94^{\circ} \mathrm{C}$ for $2 \mathrm{~min}$, followed by 35 cycles of denaturation at $94^{\circ} \mathrm{C}$ for $30 \mathrm{~s}$, and annealing at $64^{\circ} \mathrm{C}$ for $30 \mathrm{~s}$, and final extension at $72^{\circ} \mathrm{C}$ for $3 \mathrm{~min}$. For quality control, analysis of a random sample of $10 \%$ of cases and controls was repeated by different researchers, and the reproducibility was $100 \%$.

Table 1. Forward and reverse primers of $I L-10-592 \mathrm{~A} / \mathrm{C}, I L-10-819 \mathrm{C} / \mathrm{T}$, and $I L-10-1082 \mathrm{~A} / \mathrm{G}$.

\begin{tabular}{lll}
\hline & \multicolumn{1}{c}{ Sequence } \\
\hline$I L-10-592 \mathrm{~A} / \mathrm{C}$ & Forward & Reverse \\
$I L-10-819 \mathrm{C} / \mathrm{T}$ & 5'-ACACACACACAAATCCAAG-3' & 5'-ATAGGAGGTCCCTTACTTTCCTC-3' \\
$I L-10-1082 \mathrm{~A} / \mathrm{G}$ & 5'-GAAACCAAATTCTCAGTTGGC-3' & 5'-ATGACCCCTACCGTCTCTATTT-3' \\
\hline
\end{tabular}

\section{Statistical analysis}

All statistical analyses were performed using the SPSS statistical package, version 16.0 (SPSS Inc., Chicago, IL, USA) for Windows. Continuous and categorical variables are reported as the means \pm standard deviation and frequencies (\%), respectively. Demographic and clinical characteristics were compared between cases and controls by $\chi^{2}$ and Student $t$ tests. Conditional logistic regression was conducted to assess the effects of $I L-10-592 \mathrm{~A} / \mathrm{C}$, $I L-10-819 \mathrm{C} / \mathrm{T}$, and $I L-10-1082 \mathrm{~A} / \mathrm{G}$ on the risk of liver cirrhosis, with results expressed as odds ratios (ORs) and $95 \%$ confidence intervals (CIs). All $\mathrm{P}$ values were 2 -sided, and $\mathrm{P}<0.05$ was considered to be statistically significant.

\section{RESULTS}

Of the 192 patients with liver cirrhosis and 192 control subjects who were included in the study, 66 were female and 126 were male. Baseline clinical characteristics of the study participants are shown in Table 2. Patients with liver cirrhosis were more likely to have HCV and HCB and consume alcohol.

Genotype distributions of $I L-10-592 \mathrm{~A} / \mathrm{C}, I L-10-819 \mathrm{C} / \mathrm{T}$, and $I L-10-1082 \mathrm{~A} / \mathrm{G}$ among controls were found to be in Hardy-Weinberg equilibrium. Conditional regression analysis showed that individuals carrying the $I L-10-1082 \mathrm{G}$ allele had a marginally increased risk of 
liver cirrhosis, with an adjusted OR (95\%CI) of 2.14 (0.97-1.68) (Table 3). However, we did not identify a significant association between $I L-10-592 \mathrm{~A} / \mathrm{C}$ and $I L-10-819 \mathrm{C} / \mathrm{T}$ polymorphisms and the risk of liver cirrhosis.

\begin{tabular}{|c|c|c|c|c|c|c|}
\hline Variables & Patients N = 192 & $\%$ & Controls N = 192 & $\%$ & $t$ or $\chi^{2}$ & $P$ value \\
\hline \multirow{2}{*}{\multicolumn{7}{|c|}{ Gender }} \\
\hline & & & & & & \\
\hline Females & 66 & 34.4 & 66 & 34.4 & & \\
\hline Males & 126 & 65.6 & 126 & 65.6 & 0 & 1.0 \\
\hline \multicolumn{7}{|l|}{ Chronic hepatitis B } \\
\hline No & 72 & 37.5 & 174 & 90.6 & & \\
\hline Yes & 120 & 62.5 & 18 & 9.4 & 117.7 & $<0.001$ \\
\hline \multicolumn{7}{|l|}{ Chronic hepatitis C } \\
\hline No & 174 & 90.6 & 191 & 99.5 & & \\
\hline Yes & 18 & 9.4 & 1 & 0.5 & 17.0 & $<0.001$ \\
\hline \multicolumn{7}{|l|}{ Alcohol status } \\
\hline No & 102 & 53.1 & 145 & 75.5 & & \\
\hline Yes & 90 & 46.9 & 47 & 24.5 & 20.9 & $<0.001$ \\
\hline \multicolumn{7}{|l|}{ Child-Pugh score } \\
\hline A & 87 & 45.3 & & & & \\
\hline B & 78 & 40.6 & & & & \\
\hline $\mathrm{C}$ & 27 & 14.1 & & & & \\
\hline
\end{tabular}

Table 3. Association between polymorphisms of $I L-10$ genetic variants and liver cirrhosis.

\begin{tabular}{|c|c|c|c|c|c|c|}
\hline \multirow[t]{2}{*}{ SNPs } & \multicolumn{4}{|c|}{ Minor allele frequencies } & \multirow{2}{*}{$\begin{array}{c}\text { Adjusted OR }(95 \% \mathrm{CI})^{1} \\
\text { Codominant }\end{array}$} & \multirow[t]{2}{*}{$P$ value } \\
\hline & $\begin{array}{c}\text { Cases } \\
\mathrm{N}=192\end{array}$ & $\%$ & $\begin{array}{l}\text { Controls } \\
\mathrm{N}=192\end{array}$ & $\%$ & & \\
\hline \multicolumn{7}{|c|}{$I L-10-592 \mathrm{~A} / \mathrm{C}$} \\
\hline $\mathrm{AA}$ & 83 & 43.23 & 90 & 46.88 & 1.0 (Ref.) & - \\
\hline $\mathrm{AC}$ & 88 & 45.83 & 84 & 43.75 & $1.27(0.86-1.91)$ & 0.32 \\
\hline $\mathrm{CC}$ & 21 & 10.94 & 18 & 9.38 & $1.42(0.67-2.83)$ & 0.37 \\
\hline A allele & 254 & 66.15 & 264 & 68.75 & 1.0 (Ref.) & - \\
\hline $\mathrm{C}$ allele & 130 & 33.85 & 120 & 31.25 & $1.27(0.93-1.73)$ & 0.29 \\
\hline \multicolumn{7}{|c|}{$I L-10-819 \mathrm{C} / \mathrm{T}$} \\
\hline $\mathrm{CC}$ & 79 & 41.15 & 84 & 43.75 & 1.0 (Ref.) & - \\
\hline $\mathrm{CT}$ & 97 & 50.52 & 94 & 48.96 & $1.16(0.77-1.84)$ & 0.33 \\
\hline TT & 16 & 8.33 & 14 & 7.29 & $1.32(0.53-2.96)$ & 0.46 \\
\hline $\mathrm{C}$ allele & 255 & 66.41 & 262 & 68.23 & 1.0 (Ref.) & - \\
\hline $\mathrm{T}$ allele & 129 & 33.59 & 122 & 31.77 & $1.14(0.82-1.57)$ & 0.33 \\
\hline \multicolumn{7}{|c|}{$I L-10-1082 \mathrm{~A} / \mathrm{G}$} \\
\hline AA & 184 & 95.83 & 386 & 201.04 & 1.0 (Ref.) & 0.42 \\
\hline $\mathrm{AG}$ & 58 & 30.21 & 109 & 56.77 & $1.24(0.83-1.76)$ & 0.35 \\
\hline GG & 24 & 12.50 & 37 & 19.27 & $1.48(0.86-2.61)$ & 0.32 \\
\hline A allele & 426 & 110.94 & 881 & 229.43 & 1.0 (Ref.) & - \\
\hline $\mathrm{G}$ allele & 106 & 27.60 & 183 & 47.66 & $2.14(0.97-1.68)$ & 0.08 \\
\hline
\end{tabular}

${ }^{1}$ Adjusted for gender, age, chronic hepatitis B and C, and alcohol status.

\section{DISCUSSION}

In this study, we investigated the associations between 3 common genetic polymorphisms in $I L-10$ and liver cirrhosis. Our results showed that individuals carrying the $I L-10$ $1082 \mathrm{G}$ allele are only slightly associated with an increased risk of liver cirrhosis, while a non-significant association was found for $I L-10-592 \mathrm{~A} / \mathrm{C}$ and $I L-10-819 \mathrm{C} / \mathrm{T}$. A number of 
previous studies have reported an association between $I L-10$ and HBV- or HCV-related liver cirrhosis (Roy et al., 2012; Mikadze and Vashakidze, 2012; Li et al., 2012; Corchado et al., 2013). However, a study conducted in Spain reported that $I L-10$ polymorphisms are not associated with liver cirrhosis (Marcos et al., 2008). Because these studies were conducted in different populations, it is difficult to directly compare the results. The discrepancies may be due to differences in variant frequencies between races, and $I L-10$ gene polymorphisms can play different roles in the development of liver cirrhosis between populations.

IL-10 is an important immunoregulatory cytokine, which plays an important role in stimulating and suppressing the immune response produced by activated $\mathrm{T}$ cells, monocytes, B cells, and thymocytes (Helminen et al., 2001). IL-10 genetic variants are associated with higher IL-10 production (Turner et al., 1997; Suarez et al., 2003; López et al., 2010; Sofian et al., 2013). Sofian et al. (2013) reported that $I L-10$ promoter polymorphisms were not associated with HBV infection, and the A/A genotype at position -592 and the T/T genotype at position -819 were more frequently observed in patients with HBV. Moreover, $I L-10$ mRNA polymorphisms are associated with hepatocellular carcinoma, particularly in HBV- and HCVinfected individuals (Shin et al., 2003; Wang et al., 2006; Yang et al., 2011; Wei et al., 2011). Shin et al. (2003) reported that upregulated $I L-10$ accelerates the progression of chronic HBV infection in a Korean population, particularly in HCC development. A recent meta-analysis of $1012 \mathrm{HCC}$ cases and 2308 controls indicated that a polymorphism of $I L-10-592 \mathrm{~A} / \mathrm{C}$ was associated with HBV and HCC, but no association was found between $I L-10-1082 \mathrm{G} / \mathrm{A}$ and $I L-10-819 \mathrm{~T} / \mathrm{C}$ polymorphisms and the risk of HCC (Wei et al., 2011). Another meta-analysis reported that $I L-10-1082 \mathrm{G} / \mathrm{A}$ polymorphisms were related to the risk of HCC (Yang et al., 2011). Differences in sample size, study design, control selection, and genotyping methods may have contributed to the different results in these studies. In addition, the distribution of $I L-10$ genotypes showed differences for different ethnicities, which also may have affected the findings of the studies.

There were several limitations to this study. First, our study was conducted in a single hospital; thus, the samples may not be representative of patients in other centers. Second, this was a case-control study, and selection and recall biases may have affected the results. Third, liver cirrhosis is a disease caused by multiple genes and environmental factors. There may be other factors involved in the development of liver cirrhosis, and thus additional genetic and environmental factors should be considered in future studies. Finally, the sample size was relatively small, which may have limited the statistical power of identifying difference between groups.

In conclusion, we demonstrated that the $I L-10-1082 \mathrm{~A} / \mathrm{G}$ gene polymorphism is only slightly associated with the risk of liver cirrhosis, but no significant association was observed between the $I L-10-592 \mathrm{~A} / \mathrm{C}$ and $I L-10-819 \mathrm{C} / \mathrm{T}$ polymorphisms and the risk of liver cirrhosis. These findings will be useful for future studies to screen for early detection of liver cirrhosis.

\section{REFERENCES}

Andersen ES, Ruhwald M, Moessner B, Christensen PB, et al. (2011). Twelve potential fibrosis markers to differentiate mild liver fibrosis from cirrhosis in patients infected with chronic hepatitis C genotype 1. Eur. J. Clin. Microbiol. Infect. Dis. 30: 761-766.

Corchado S, Márquez M, Montes de OM, Romero-Cores P, et al. (2013). Influence of genetic polymorphisms of tumor necrosis factor $\alpha$ and interleukin 10 genes on the risk of liver cirrhosis in HIV-HCV coinfected patients. PLoS One 8: e66619. 
European Association for the Study of the Liver (EASL) (2010). EASL clinical practice guidelines on the management of ascites, spontaneous bacterial peritonitis, and hepatorenal syndrome in cirrhosis. J. Hepatol. 53: 397-417.

Helminen ME, Kilpinen S, Virta M and Hurme M (2001). Susceptibility to primary Epstein-Barr virus infection is associated with interleukin-10 gene promoter polymorphism. J. Infect. Dis. 184: 777-780.

Koziel MJ (2005). Cellular immune responses against hepatitis C virus. Clin. Infect. Dis. 41 (Suppl 1): S25-S31.

Li QY, Guo ZZ, Liang J, Zhang W, et al. (2012). Interleukin-10 genotype correlated to deficiency syndrome in hepatitis B cirrhosis. Evid. Based Complement. Alternat. Med. 2012: 298925.

Lippitz BE (2013). Cytokine patterns in patients with cancer: a systematic review. Lancet Oncol. 14: e218-e228.

López P, Gutiérrez C and Suárez A (2010). IL-10 and TNF $\alpha$ genotypes in SLE. J. Biomed. Biotechnol. 2010: 838390.

Marcos M, Pastor I, González-Sarmiento R and Laso FJ (2008). Interleukin-10 gene polymorphism is associated with alcoholism but not with alcoholic liver disease. Alcohol Alcohol. 43: 523-528.

Mikadze I and Vashakidze E (2012). The role of interleukin-10 in patients with HCV infection. Georgian. Med. News 30-33.

Reuss E, Fimmers R, Kruger A, Becker C, et al. (2002). Differential regulation of interleukin-10 production by genetic and environmental factors-a twin study. Genes Immun. 3: 407-413.

Roy N, Mukhopadhyay I, Das K, Pandit P, et al. (2012). Genetic variants of TNF $\alpha$, IL10, IL1 $\beta$, CTLA4 and TGF $\beta 1$ modulate the indices of alcohol-induced liver injury in East Indian population. Gene 509: 178-188.

Shin HD, Park BL, Kim LH, Jung JH, et al. (2003). Interleukin 10 haplotype associated with increased risk of hepatocellular carcinoma. Hum. Mol. Genet. 12: 901-906.

Sofian M, Kalantar E, Aghakhani A, Hosseini S, et al. (2013). No correlation between interleukin-10 gene promoter polymorphisms and hepatitis B virus infection outcome. Hepat. Mon. 13: e8803.

Suarez A, Castro P, Alonso R, Mozo L, et al. (2003). Interindividual variations in constitutive interleukin-10 messenger RNA and protein levels and their association with genetic polymorphisms. Transplantation 75: 711-717.

Tsai CW, Tsai MH, Shih LC, Chang WS, et al. (2013). Association of interleukin-10 (IL10) promoter genotypes with nasopharyngeal carcinoma risk in Taiwan. Anticancer Res. 33: 3391-3396.

Turner DM, Williams DM, Sankaran D, Lazarus M, et al. (1997). An investigation of polymorphism in the interleukin-10 gene promoter. Eur. J. Immunogenet. 24: 1-8.

Wang J, Ni H, Chen L and Song WQ (2006). Interleukin-10 promoter polymorphisms in patients with hepatitis B virus infection or hepatocellular carcinoma in Chinese Han ethnic population. Hepatobiliary Pancreat. Dis. Int. 5: 60-64.

Wei YG, Liu F, Li B, Chen X, et al. (2011). Interleukin-10 gene polymorphisms and hepatocellular carcinoma susceptibility: a meta-analysis. World J. Gastroenterol. 17: 3941-3947.

Yang Y, Luo C, Feng R and Bi S (2011). The TNF- $\alpha$, IL-1B and IL-10 polymorphisms and risk for hepatocellular carcinoma: a meta-analysis. J. Cancer Res. Clin. Oncol. 137: 947-952. 